\title{
Corrigendum: "The GOddard SnoW Impurity Module (GOSWIM) for the NASA GEOS-5 Earth System Model: Preliminary Comparisons with Observations in Sapporo, Japan"
}

\author{
Teppei J. Yasunari ${ }^{1}$, K.-M. Lau ${ }^{2,3}$, Sarith P. P. Mahanama ${ }^{4,3}$, Peter R. Colarco ${ }^{3}$, Arlindo M. da Silva ${ }^{3}$, \\ Teruo Aoki ${ }^{5}$, Kazuma Aoki ${ }^{6}$, Naoto Murao ${ }^{1}$, Sadamu Yamagata ${ }^{1}$, and Yuji Kodama ${ }^{7}$ \\ ${ }^{1}$ Faculty of Engineering, Hokkaido University, Sapporo, Japan \\ ${ }^{2}$ Earth System Science Interdisciplinary Center, University of Maryland, College Park MD, USA \\ ${ }^{3}$ NASA Goddard Space Flight Center, Greenbelt, MD, USA \\ ${ }^{4}$ Science Systems and Applications, Inc., Lanham, MD, USA \\ ${ }^{5}$ Meteorological Research Institute, Tsukuba, Japan \\ ${ }^{6}$ Faculty of Science, University of Toyama, Toyama, Japan \\ ${ }^{7}$ National Institute of Polar Research, Tokyo, Japan
}

(Citation: Yasunari, T. J., K.-M. Lau, S. P. P. Mahanama, P. R. Colarco, A. M. da Silva, T. Aoki, K. Aoki, N. Murao, S. Yamagata, and Y. Kodama, 2016: Corrigendum: "The GOddard SnoW Impurity Module (GOSWIM) for the NASA GEOS-5 Earth System Model: Preliminary comparisons with observations in Sapporo, Japan”. SOLA, 12, c1, doi:10.2151/sola.2016-014.)

In Yasunari et al. (2014), there were errors in Fig. 3. They inadvertently compared the simulated particulate organic matter (POM or OM) in snow to the measured organic carbon (OC) in snow by Aoki et al. (2011). Strictly speaking, the model mass ratio between POM and OC was a factor of 1.4 as mentioned for the GEOS-4 treatment in Colarco et al. (2010), which is a typical OM/ OC mass conversion treatment on atmospheric aerosol discussion (e.g., Chin et al. 2009). Yasunari et al. (2014) actually did treat the POM mass in their OC snow-darkening calculations in the model because of using the POM depositions from the GOCART module in GEOS-5 as they were. Therefore, the modeled OC mass concentrations in snow in Fig. 3 of Yasunari et al. (2014) should have been divided by 1.4 (or the observed pure OC by Aoki et al. (2011) should be multiplied by 1.4) for proper comparisons. However, this treatment had minor impact on the discussions and conclusions by Yasunari et al. (2014). Hence, we just briefly mention this point here for readers as a corrigendum. The OC, which was referred in Qian et al. (2015) and Yasunari et al. (2015) on the GEOS-5 related descriptions and/or the discussions on snowdarkening effect, also represented POM (or OM) mass in snow as well.

\section{References}

Aoki, T., K. Kuchiki, M. Niwano, Y. Kodama, M. Hosaka, and T. Tanaka, 2011: Physically based snow albedo model for calculating broadband albedos and the solar heating profile in snowpack for general circulation models. J. Geophys. Res., 116, D11114, doi:10.1029/2010JD015507.

Chin, M., T. Diehl, O. Dubovik, T. F. Eck, B. N. Holben, A. Sinyuk, and D. G. Streets, 2009: Light absorption by pollution, dust, and biomass burning aerosols: a global model study and evaluation with AERONET measurements. Ann. Geophys., 27, 3439-3464, doi:10.5194/angeo-27-3439-2009.

Colarco, P., A. da Silva, M. Chin, and T. Diehl, 2010: Online simulations of global aerosol distributions in the NASA GEOS-4 model and comparisons to satellite and ground-based aerosol optical depth. J. Geophys. Res., 115, D14207, doi:10.1029/ 2009JD012820.

Qian, Y., T. J. Yasunari, S. J. Doherty, M. G. Flanner, W. K. M. Lau, J. Ming, H. Wang, M. Wang, S. G. Warren, and R. Zhang, 2015: Light-absorbing particles in snow and ice: Measurement and modeling of climatic and hydrological impact. Adv. Atmos. Sci., 32, 64-91, doi:10.1007/s00376014-0010-0.

Yasunari, T. J., K.-M. Lau, S. P. P. Mahanama, P. R. Colarco, A. M. da Silva, T. Aoki, K. Aoki, N. Murao, S. Yamagata, and Y. Kodama, 2014: The GOddard SnoW Impurity Module (GOSWIM) for the NASA GEOS-5 Earth System Model: Preliminary comparisons with observations in Sapporo, Japan. SOLA, 10, 50-56, doi:10.2151/sola.2014-011.

Yasunari, T. J., R. D. Koster, W. K. M. Lau, and K.-M. Kim, 2015: Impact of snow darkening via dust, black carbon, and organic carbon on boreal spring climate in the Earth system. J. Geophys. Res. Atmos., 120, 5485-5503, doi:10.1002/2014 JD022977.

Manuscript received 29 January 2016, accepted 29 January 2016 SOLA: https://www.jstage.jst.go.jp/browse/solal

Corresponding author: Teppei J. Yasunari, Faculty of Engineering, Hokkaido University, Kita 13 Nishi 8, Kita-ku, Sapporo 060-8628, Japan. E-mail: t.j.yasunari@eng.hokudai.ac.jp. (C2016, the Meteorological Society of Japan. 